\title{
Rapid on-site evaluation (ROSE) in pancreatic cancer diagnosis: Doing more with less
}

\section{Enrico Giarnieri, Antonella Carnuccio, Domenico Galasso, Rita Mancini, Elisabetta Carico, Emilio Di Giulio, Maria Rosaria Giovagnoli}

Most of pancreatic masses are represented by neoplastic processes, primarily ductal adenocarcinoma and less frequently neuroendocrine tumor, lymphoma and metastasis. On the contrary, non-neoplastic lesions are represented by chronic, autoimmune pancreatitis and cysts $[1,2]$. Pancreatic cancer is the fourth and fifth most common cancer in men and women, respectively [3]. Due to local invasion or distant metastasis, only $15^{-20} \%$ of patients are surgical candidates at presentation. Among them, the five-year survival rate is only 10-15\% [4]. About $70 \%$ of pancreatic cancers develop in the head while 10$20 \%$ in the body and tail [5]. In many cases, pancreatic cancer is diagnosed in the advanced stage of the disease and at this point the tumor cannot be surgically excised. In fact, at the moment of diagnosis, $52 \%$ patients show distant disease and 26\% have regional spread [6]. Endoscopic ultrasound-guided fine-needle aspiration (EUS-FNA) is a rapid, safe, cost-effective and accurate technique to evaluate and stage pancreatic tumors [7]. In addition, this technique has proved a very useful in discriminating between suspicious lesions, inflammation and cancer, especially adenocarcinomas. The EUS-FNA demonstrates a low percentage of major complications and a low risk of disseminating neoplastic cells when compared to the percutaneous approach. Cytological evaluation may have some disadvantages such as a limited

Enrico Giarnieri ${ }^{1}$, Antonella Carnuccio ${ }^{2}$, Domenico Galasso $^{3}$, Rita Mancini ${ }^{1}$, Elisabetta Carico ${ }^{1}$, Emilio Di Giulio², Maria Rosaria Giovagnoli ${ }^{1}$

Affiliations: 'University of Rome "Sapienza", Cytopathology Unit, Sant'Andrea Hospital, Rome, Italy; 'University of Rome "Sapienza", Digestive Endoscopy Unit, Sant'Andrea Hospital, Rome, Italy; ${ }^{3}$ University of CattolicaSacroCuore, Digestive Endoscopy Unit, A. Gemelli Hospital, Rome, Italy Corresponding Author: Enrico Giarnieri, MD, University of Rome Sapienza, Department of Clinical and Molecular Medicine, UOD Cytopathology, Sant'Andrea Hospital, Rome, Italy, 00198; Email:enrico.giarnieri@uniroma1.it

Received: 26 June 2015

Published: 03 September 2015 amount of material to make a diagnoses especially when differentiation between different tumor types is requested. Authors reported that EUS-FNA may be inconclusive or doubtful in up to 20\% cases [8-13]. Explanations could be: (a) an inexperienced endosonographer, (b) small tumors in which it is often difficult to perform a biopsy and cytopathology performances are lower, (c) the absence of a cytopathologist to make on site sampling evaluation, (d) the presence of blood in the sample, (e) the diagnosis may be difficult in cases of well-differentiated adenocarcinoma and reactive atypia, (f) gastric and duodenum cell contamination. Today there are technical improvements, like new generations of needles and ultrasound machines, immunodetection and molecular biology which offer the possibility of diagnostic accuracy.

One of the most important effects of teamwork is to facilitate a rapid diagnosis for the patient. In this case, the synergy between the cytopathologist and experienced ultrasonographer, demonstrates that it is possible to increase the accuracy of diagnosis. In our experience, the advantage of the rapid on-site evaluation (ROSE) during pancreatic EUS-FNA has been the following:

(a) real time confirmation of neoplastic cell specimens

(b) adequacy of the sample material for the purpose of molecular or immunocytochemistry analysis

(c) contribution to the preoperative staging in the case of multifocal/multicentric tumors, lymph node involvment or distant metastasis

(d) interdisciplinarity, evaluation and integration between clinical, radiological, laboratory and pathological data

(e) contribution to the trainees for a faster learning curve

(f) contribution to evolution of interventional maneuvers, for example the choice of trajectory, type and degrees of suction in the mass

In a previous study, we observed that one important factor impacting on transbronchial needle aspiration (TBNA) sensitivity, during fiberoptic bronchoscopy or mediastinoscopy, is the rapid on-site cytological examination (ROSE) [14]. The combination of EUSFNA and ROSE not only increases the percentage of 
positive diagnoses, but also allows a significant reduction in expenses and time. This is an important factor because hospital managers have to respond not only for the efficacy, but also for the cost of their work. The technological progress has provided a great number of increasingly sophisticated and expensive tools. The task of the modern physician is to use equipment suitable for the patient's needs, based on a careful evaluation of costs, benefits and risk-benefit ratio. Our experience with on-site cytology evaluation and EUS-FNA in pancreatic cancer, shows there are some weak points: a limitation of the available resources of personnel, and an increase in the waiting-time in cases that are difficult to diagnose. To achieve adequate performance, EUS-FNA must be carried out in highly-experienced centers, with the appropriate equipment and possibly with the aid of an on-site cytopathologist. However, on-site cytopathology interpretation may not be available in many centers.

Chang et al. reported that in the presence of an onsite cytopathology assistant, during EUS-FNA, adequate specimens were obtained in $100 \%$ patients. On the contrary, the same study observed that absence of an on-site cytologist resulted in $29 \%$ of patients requiring a second procedure to obtain an adequate specimen [15]. Erickson et al observed, that when a cytopathologist was not on-site, in addition to prolonging procedure time and potentially increasing the procedural risk using multiple needle passes, the diagnostic yield of EUS-FNA dropped by $10-15 \%$ [16]. Tournoy et al. demonstrated that EUS-FNA with on-site cytopathology in mediastinal lymphadenopathy interpretation reported a diagnostic accuracy of 92\% [17]. Bruno et al. observed that without and with on-site cytological examination, the application of TBNA in mediastinal lymphadenopathies determined a sensitivity of $65 \%$ and $80 \%$, respectively. The same authors conclude that ROSE significantly improved the sensitivity of TBNA because the bronchoscopist can change the needle insertion point [14]. In our experience using EUS-FNA with ROSE in pancreatic suspected masses, it was possible to obtain a definitive diagnosis or an indication to continue with additional samples. Overall sensitivity, specificity, positive predictive value (PPV), negative predictive value (NPV) and diagnostic accuracy of cytology samples from EUS-FNA were 80.8\%, 100\%, $100 \%, 72.2 \%$ and $87.2 \%$, respectively (data not shown). The sensitivity and accuracy of combined histology and cytology was higher than histology or cytology alone. Histologic analysis revealed malignant cells that were not diagnosed by cytology, especially when there were excess of blood clots. In these cases, the blood material was fixed in formalin directly.

The literature reports the risk of a false negative cytology during EUS-FNA in patients with chronic pancreatitis $[18,19]$, although this is not the only cause. Cell contamination during needle passages and the presence of excess blood covering the slide during onsite evaluation, represent other possible causes of false negative. The former, depends on the cytopathologist's experience. During the passages, the needle can sample single or groups of cells from stomach or duodenum, which are sometimes in layers, and it is difficult to distinguish them from the pancreatic tissues. The second problem can be excessive blood on the slide which covers the cells. The amount of blood may depend on the type of needle used. In this case, to prevent blood coagulation, the speed with which the material from the needle is smeared on the slide is very important. Differential diagnosis can be difficult because cells remain trapped in the fibrin. Even in experienced hands, these events may be encountered during EUS-FNA. Standardized terminology and nomenclature for pancreatic cytology provides guidance for the diagnosis of pancreatic lesions. Correlation between morphology, biological features and management recommendations is crucial in the presence of pancreatic massess and cysts. About that, an useful terminology scheme has been recently proposed [20]. This scheme allows the pathologist to classify lesions with a low grade of differentiation and slight atypias as compared to ductal pancreatic lesions frequently associated with marked cytological alterations. Following ROSE, there can be cases of specimens classified as inconclusive, indeterminate, or negative. For these cases, ancillary procedures including immunocytochemistry, fluorescence in situ hybridization, genetic analysis for neoplasia-specific mutations, and sequential mutational analysis are potentially useful in cytological interpretation.

In conclusion, EUS-FNA offers great possibilities for future technological development like increasingly defined imaging and more flexible needles to take samples from areas difficult to access. The ROSE is a method that, in its technical simplicity, has many advantages in terms of adequacy of cell material and preoperative cytologic diagnosis. In some cases, with very few cells it is possible to carry out a number of diagnostic procedures for an accurate diagnosis. However, the pathologist must have experience in this specific field and work within a team where it is possible to have clinical and imaging information about the patient. After a careful morphological assessment, if the cytology alone is not conclusive, it may be better to apply ancillary tests, especially if biopsy material is not available and the cytological material is the only choice for diagnosis and therapy decision making.

Keywords: Cancer, Endoscopic ultrasound-guided fineneedle aspiration (EUS-FNA), Pancreas, Rapid on-site evaluation (ROSE)

\section{How to cite this article}

Giarnieri E, Carnuccio A, Galasso D, Mancini R, Carico E, Giulio ED, Giovagnoli MR. Rapid on-site evaluation (ROSE) in pancreatic cancer diagnosis: Doing more with less. Oncocytology 2015;5:17-20. 
Article ID: 100009 OCYEG2O15

$* * * * * * * * *$

doi:10.5348/OCY-2015-9-ED-3

$* * * * * * * * *$

\section{Author Contributions}

Enrico Giarnieri - Substantial contributions to conception and design, Acquisition of data, Analysis and interpretation of data, Drafting the article, Revising it critically for important intellectual content, Final approval of the version to be published

Antonella Carnuccio - Analysis and interpretation of data, Revising it critically for important intellectual content, Final approval of the version to be published Domenico Galasso - Analysis and interpretation of data, Revising it critically for important intellectual content, Final approval of the version to be published

Rita Mancini - Analysis and interpretation of data, Revising it critically for important intellectual content, Final approval of the version to be published

Elisabetta Carico - Analysis and interpretation of data, Revising it critically for important intellectual content, Final approval of the version to be published

Emilio Di Giulio - Analysis and interpretation of data, Revising it critically for important intellectual content, Final approval of the version to be published

Maria Rosaria Giovagnoli - Analysis and interpretation of data, Revising it critically for important intellectual content, Final approval of the version to be published

\section{Guarantor}

The corresponding author is the guarantor of submission.

\section{Conflict of Interest}

Authors declare no conflict of interest.

\section{Copyright}

(C) 2015 Enrico Giarnieri et al. This article is distributed under the terms of Creative Commons Attribution License which permits unrestricted use, distribution and reproduction in any medium provided the original author(s) and original publisher are properly credited. Please see the copyright policy on the journal website for more information.

\section{REFERENCES}

1. Levy MJ, Wiersema MJ, Chari ST. Chronic pancreatitis: focal pancreatitis or cancer? Is there a role for FNA/biopsy? Autoimmune pancreatitis. Endoscopy 2006 Jun;38 Suppl 1:S30-5.

2. Dite P, Trna J, Novotny I. Autoimunne pancreatitis. Minerva Gastroenterol Dietol 2008 Dec;54(4):359-
64.

3. Bray F, Ren JS, Masuyer E, Ferlay J. Global estimates of cancer prevalence for 27 sites in the adult population in 2008. Int J Cancer 2013 Mar 1;132(5):1133-45.

4. Oettle H, Post S, Neuhaus P, et al. Adjuvant chemotherapy with gemcitabine vs observation in patients undergoing curative-intent resection of pancreatic cancer: a randomized controlled trial. JAMA 2007 Jan 17;297(3):267-77.

5. Ros PR, Mortelé KJ. Imaging features of pancreatic neoplasms. JBR-BTR 2001;84(6):239-49.

6. American Cancer Society. Cancer facts and Figures 2010. Atlanta. [Availabe at: http://www.cancer.org/ research/cancerfactsfigures/cancerfactsfigures/ cancer-facts-and-figures-2010]

7. Siddiqui AA, Brown LJ, Hong SK, et al. Relationship of pancreatic mass size and diagnostic yield of endoscopic ultrasound-guided fine needle aspiration. Dig Dis Sci 2011 Nov;56(11):3370-5.

8. Buscail L, Faure P, Bournet B, Selves J, Escourrou J. Interventional endoscopic ultrasound in pancreatic diseases. Pancreatology 2006;6(1-2):7-16.

9. Savides TJ, Donohue M, Hunt G, et al. EUSguided FNA diagnostic yield of malignancy in solid pancreatic masses: a benchmark for quality performance measurement. Gastrointest Endosc 2007 Aug;66(2):277-82.

10. Al-Haddad M, Eloubeidi MA. Interventional EUS for the diagnosis and treatment of locally advanced pancreatic cancer. JOP 2010 Jan 8;11(1):1-7.

11. Yoshinaga S, Suzuki H, Oda I, Saito Y. Role of endoscopic ultrasound-guided fine needle aspiration (EUS-FNA) for diagnosis of solid pancreatic masses. Dig Endosc 2011 May;23 Suppl 1:29-33.

12. Okano K, Oshima M, Yachida S, et al. Factors predicting survival and pathological subtype in patients with ampullary adenocarcinoma. J Surg Oncol 2014 Aug;110(2):156-62.

13. Eloubeidi MA, Varadarajulu S, Desai S, Wilcox CM. Value of repeat endoscopic ultrasound-guided fine needle aspiration for suspected pancreatic cancer. $\mathrm{J}$ Gastroenterol Hepatol 2008 Apr;23(4):567-70.

14. Bruno P, Ricci A, Esposito MC, et al. Efficacy and cost effectiveness of rapid on site examination (ROSE) in management of patients with mediastinal lymphadenopathies. Eur Rev Med Pharmacol Sci 2013 Jun;17(11):1517-22.

15. Chang KJ, Katz KD, Durbin TE, et al. Endoscopic ultrasound-guided fine-needle aspiration. Gastrointest Endosc 1994 Nov-Dec;40(6):694-9.

16. Erickson RA, Sayage-Rabie L, Beissner RS. Factors predicting the number of EUS-guided fine-needle passes for diagnosis of pancreatic malignancies. Gastrointest Endosc 2000 Feb;51(2):184-90.

17. Tournoy KG, Praet MM, Van Maele G, Van Meerbeeck JP. Esophageal endoscopic ultrasound with fineneedle aspiration with an on-site cytopathologist: high accuracy for the diagnosis of mediastinal lymphadenopathy. Chest 2005 Oct;128(4):3004-9.

18. Varadarajulu S, Tamhane A, Eloubeidi MA. Yield of EUS-guided FNA of pancreatic masses in the presence or the absence of chronic pancreatitis. Gastrointest Endosc 2005 Nov;62(5):728-36; quiz 751, 753. 
20. Pitman MB, Centeno BA, Ali SZ, et al. Standardized terminology and nomenclature for pancreatobiliary cytology: The Papanicolaou Society of Cytopathology Guidelines. Cytojournal 2014 Jun 2;11(Suppl 1):3.
Access full text article on other devices

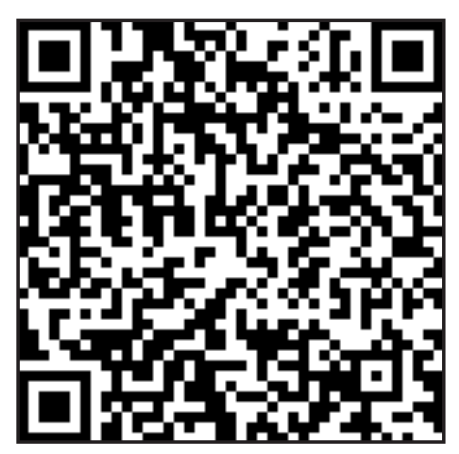

Access PDF of article on other devices

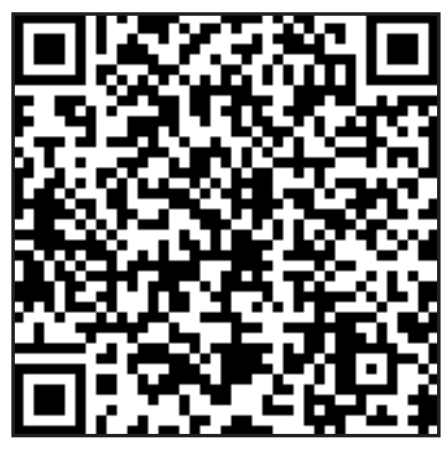

